\title{
Latidos sentipensantes de un maestro como forma de resistencia a la calidad de la educación ${ }^{1}$
}

\section{Heartbeats sentipensantes of a teacher as a form of resistance to the quality of education}

Deyby Rodrigo Espinosa Gómez*

Recibido: 9 de abril de 2020 Aceptado: 22 de junio de 2020 Publicado: 30 de septiembre de 2020

To cite this article: Espinosa, D. R. (2020). Latidos sentipensantes de un maestro como forma de resistencia a la calidad de la educación. Márgenes, Revista de Educación de la Universidad de Málaga, 1 (3), 291-313

DOI: https://doi.org/10.24310/mgnmar.v1i3.8510

\section{RESUMEN}

La presente reflexión propone una lectura crítica sobre la influencia delos discursos, políticas y reglamentaciones de la calidad de la educación en la escuela, los cuales consideran a la educación un bien esencialmente privado y cuyo valor es ante todo económico. En primer lugar, se narra la experiencia de un maestro de una institución educativa privada con los discursos de la calidad de la educación, en segundo lugar, se problematizan los "antilatidos de la calidad", entendiendo por estos aquellos efectos de los discursos de la calidad en la educación que actúan en detrimento del proceso enseñanza-aprendizaje. Finalmente, se plantean los "latidos sentipensantes de un maestro y la pedagogía social”, refiriéndose a aquellos elementos pedagógicos para pensar otras posibles formas de resistencia en defensa de una escuela que recupere la educación como valor social. Así pues, los latidos en la presente reflexión es un llamado para que las maestras y los maestros conformemos espacios de criticidad para reflexionar, cuestionar y transformar con nuestras manos y acciones, desde el pensamiento y el corazón, la visión reduccionista, eficientista y mercantilista de la educación que se nos ha querido imponer desde el sistema capitalista neoliberal.

Palabras clave: calidad de la educación; maestro; latidos sentipensantes; práctica pedagógica sentipensante; pedagogía social

\section{ABSTRACT}

This reflection proposes a critical reading on the influence of discourses, policies and regulations on the quality of education in school, which consider education as an essentially private good and whose value is above all economic. In the first place, the experience of a teacher from a private educational institution is narrated with the discourses of the quality of education, secondly, the "quality antilatidos" are problematized, understanding by those effects of the discourses of the quality in education that act to the detriment of the teaching-learning process. Finally, the "sentipensante heartbeats of a teacher and social pedagogy" are raised, referring to those pedagogical elements to think of other possible forms of resistance in defense of a school that recovers

1 La presente experiencia reflexiva deriva del Proyecto de Investigación de Maestría: Práctica Pedagógica Sentipensante como resistencia ante los discursos de la calidad de la educación: La Experiencia Biográfica Narrativa de un Maestro de una institución educativa privada. Proyecto Magna Cum Laude de la facultad de Educación de la Universidad de Antioquia. Medellín-Colombia. ¡Te invito a leerla! Miembro grupo de investigación Unipluriversidad. 


\section{E X P E R I E N C I A S}

education as a social value. Thus, the beats in this reflection is a call for teachers to form critical spaces to reflect, question and transform with our hands and actions, from the thought and the heart, the reductionist, efficient and mercantile vision of the education that has been imposed on us from the neoliberal capitalist system

Keywords: quality of education; teacher; beats sentipensantes; sentipensante pedagogical practice; social pedagogy

Donde el corazón te lleve (sin perder la razón del corazón):

“A mi maestro Hader Calderón Serna, un maestro de y para la vida que me ha enseñado la esperanza en la educación; y finalmente, a mis estudiantes y maestros colombianos, no olviden que por difícil que parezca la educación puede transformarse, el maestro es esperanza, y si él cambia, todo cambia a su alrededor"

\section{NARRAR-ME PARA PENSAR-ME EN LOS DISCURSOS DE LA CALIDAD}

En el 2014 llegué a laborar a un colegio. Una institución educativa de carácter privado, que se ha caracterizado por sus altos resultados en las pruebas estatales. Me sentía el maestro de sangre nueva que llega con tintes de sueños y palabras transformativas aprendidas en una universidad; sentía las miradas en mí como aquél del cual se espera mucho o se quiere poner a prueba. Al pasar los días me encontré con un sistema educativo que regula y condiciona aquellos tintes, discursos y prácticas pedagógicas.

El día a día se convertía en un ¡Silencio! ¿Qué es este desorden? ¿Qué es este bullicio? "Profesor, recuerde que los estudiantes deben estar en orden en las filas, y la clase debe tener la disciplina que ha caracterizado a la institución durante todos estos años”.

Para serles franco, me sentía incómodo, pues siempre he pensado que una clase debe ser participativa; que la palabra debe escucharse; y que el otro, a veces en el bullicio, deja aflorar muchas emociones, comportamientos y hasta realidades más profundas de su contexto, realidades que suele ignorar la escuela. A esa rigurosa disciplina debí sumar adaptarme al diseño de pruebas estandarizadas, pruebas de carácter ICFES ${ }^{2}$, de selección múltiple; comprendí que para la institución era muy importante la preparación para la vida evaluativa de sus estudiantes, evaluación que comenzaba desde los primeros grados, y que en los grados superiores han hecho destacar al colegio como la mejor institución educativa a nivel municipal.

Con el pasar de los días como maestro, comencé a experimentar transformaciones en el mundo de las ideas que, como un imán, atrae a su campo magnético a la excelencia y a los resultados, escuelas más competitivas y estandarizadas al ritmo mundial. En este sentido, me autocriticaba, ya que mi práctica pedagógica se encontraba en una zona de confort, sumergida a diseño de pruebas, calificaciones, números y más números. Situación que se agudizó en la institución

2 El Icfes es una empresa estatal de carácter social, vinculada al Ministerio de Educación Nacional, y naturaleza especial, implementa servicios de evaluación de la educación en todos sus niveles (Exámenes de Estado). 
educativa en el año 2015 con la implementación del "Día E” excelencia, y evaluación de los resultados institucionales priorizando en el fortalecimiento de las áreas de Matemáticas y Lenguaje, dejando de lado la pregunta por el contexto, una crítica que comenzó a generar múltiples tensiones en mi ser maestro.

Al querer diseñar espacios para el diálogo sobre lo pedagógico, el contexto y la investigación, me encontré una gran dificultad, pues el poco tiempo que tenía, junto con mis compañeros, se destinaba al diligenciamiento de los observadores, planillas, citaciones a padres y diligenciamiento de formatos. Encontré que el dinamismo en las manos de la calidad me sumergía en las líneas de una práctica individualista y competitiva; sentía inseguridad en mi praxis al estar observado todo el tiempo. En espacios educativos emergían palabras reduccionistas y comparativas que borraban y ponían en cuestión esa idea maravillosa aprendida en mi formación universitaria de que la educación son ritmos diversos, y comencé a escuchar, otras voces que perturbaban mi conciencia: “x estudiante es mejor que el resto", "el maestro x, es un maestro de calidad”, “en x área están bajando los resultados en pruebas, qué pasa con los maestros de esta área”.

Mi práctica pedagógica era vigilada y supervisada constantemente; así mismo, me sumergía en lo que tanto criticaba de los maestros colombianos en mi época universitaria, en un maestro reproductor de pruebas estandarizadas. ¡Y cómo no hacerlo, pues la supervisión y la premura ante la cantidad de trabajos así lo demandaba! Poco a poco esta relación me daba a entender que el centro de la educación era la competencia; bastaba simplemente ver las reuniones de profesores y directivos con porcentajes comparativos respecto a cada periodo, y cifras de años anteriores. El día E, en pro de fortalecer el Índice Sintético de la Calidad Educativa, priorizaba en indicadores y resultados homogeneizadores de las diferencias humanas, dejando de lado los problemas contextuales como institución.

Encontraba cada vez más a un maestro regulado y recargado de tareas y formatos, acosado de exigencias de los dispositivos evaluativos, y sometido a simulacros de acreditación. En los avatares y aceleres de la calidad, desaparecían como por arte de magia los tiempos para pensar la pedagogía y la práctica pedagógica, para investigar sobre la educación y las necesidades de su contexto, estos tiempos eran reemplazados por el diligenciamiento de listados, planillas y parámetros solicitados por la calidad de la educación (Espinosa, 2016).

Me llenaba de desconsuelo ver maestros responsables de más de 14 planillas (grupos), cada planilla entre 38 o 40 estudiantes; maestros con turnos de más de nueve horas diarias con un salario que no llegaba ni a los dos salarios mínimos; maestros cansados y poco valorados.

A propósito de lo anterior, me encontré con una incoherencia discursiva, pedagógica y practicada en la institución educativa privada, pues su discurso habla de la importancia de reconocer

3 Día de la Excelencia educativa, jornada implementada desde el año 2015 por el Ministerio de Educación colombiano en los colegios úblicos y privados revisando sus desempeños en calidad educativa. Con esta herramienta se comienza a implementar el "índice Sintético de la Calidad Educativa" con la cual se busca medir la calidad de la educación en los niveles de primaria, secundaria y media a través de cuatro componentes: Progreso, eficacia, desempeño y ambiente escolar. Esta estrategia es adoptada del Ministerio de Educación brasilero sin ningún respeto a las diferencias contextuales, es una acción puntual que aborda los resultados, pero desconoce las realidades educativas del país, fomenta la cultura del eficientismo y las competencias. Esta herramienta ha agudizado la brecha estigmatizadora entre la educación pública y privada, así mismo, lo que es buena y mala educación de acuerdo a la lupa de la calidad de la educación. 
las diferencias y convivir en igualdad, y, por otro lado, su evaluación estandariza, promueve las competencias, y hace de forma subrepticia entre su discurso estudiantes y maestros inseguros, temerosos de sus capacidades, rotulándolos como "buenos” y “malos”. En esa incoherencia discursiva, puedo señalar, además, algo que no es tan visible en su discurso, y es precisamente las condiciones laborales de los maestros, una situación laboral que es inestable y de incertidumbre, en ella no existe un escalafón salarial, al terminar el estudio de posgrado muchos son forzados u optan por abandonar la institución pues no se presenta un reconocimiento salarial. Al finalizar el año escolar, llega el "día de la incertidumbre”, así lo llamamos nosotros los maestros del sector privado, ese día nos enfrentamos a un gran temor, ¿nuestro contrato será renovado o cancelado?, es desgarrador ver salir a compañeros entre lágrimas y desconsuelo, mientras se nos recuerda que se vive un sistema de méritos y resultados.

En los colegios privados no existe sindicatos, ni mucho menos marchas por las condiciones laborales de los maestros como lo hace el sector público. Mientras los docentes del público marchan por las calles de mi Colombia reclamando sus derechos, existe otra realidad de maestros en colegios privados, que deben continuar con sus labores, muchas en condiciones y salarios injustos, y con excesos de compromisos en pro de la excelencia; a esto le sumo el temor de hablar y ser despedido de sus planteles educativos.

Cada año debemos asistir a un encuentro de colegios privados; en ella se habla de la importante tarea que tenemos como maestros con las futuras generaciones, en este espacio suele reiterarse que falta más pasión, más dedicación y esfuerzo por parte de los docentes, sumado a esto, me sorprende que mientras se expone un ideal de maestro privado se deja de lado preguntas fundamentales al interior de las instituciones: ¿Cómo se siente el maestro?, ¿Qué condiciones laborales tiene?, ¿el maestro privado es feliz?, ¿Qué necesita el maestro de educación privada? Son interrogantes que muchos maestros deben callar. Así mismo, sorprende la falta de regulación a las condiciones laborales de los maestros de institución privada por parte del Ministerio de Educación Nacional, regulación que parece reemplazarse por la supervisión en los resultados de pruebas estatales.

Mientras este relato se escribía en mi mente, mi corazón se preocupaba, sobre todo, ya que mi práctica como maestro no marchaba de acuerdo a mi filosofía humanista que había heredado de mis experiencias y mi formación; conmigo caminaba una carga de experiencias y tejidos humanistas que se resistían a ver la escuela como una empresa y a los estudiantes como tornillos. Cada vez sentía mi inconformidad ante la dinámica del sistema de calidad que pretende educar a las personas en equidad mientras prioriza la competitividad; habla de diversidad y establece unos parámetros únicos de calidad educativa para todos; pretende que los estudiantes sean creativos, y en las pruebas estandarizadas estos deben responder de memoria sin importar sus necesidades (Espinosa, 2017).

Mi discurso pedagógico entraba en tensión con las situaciones anteriormente mencionadas, ya que sentía que el acelere del sistema invisibilizaba y no permitía la riqueza de leer y escuchar al otro en la escuela. Por ello, como maestro, comencé a reconocer las huellas del problema, y desde allí, elevar mi voz por una educación diferente, a re-pensar mi práctica como maestro. 


\section{SENTIPENSAR LAS HUELLAS DEL PROBLEMA: LA CALIDAD DE LA EDUCACIÓN UN CONCEPTO A PENSARSE}

Mi reflexión se inscribe en la investigación cualitativa y en el paradigma sociocrítico, ya que adopta como base la idea de la teoría crítica, que no es un enfoque puramente empírico, ni sólo interpretativo, ya que busca dar sentido y comprender la experiencia vivida y narrada como carácter transformativo. Implemento el método biográfico narrativo el cual parte de la experiencia de vida, en este caso, mi experiencia, una experiencia que se construye en el reconocimiento y encuentro con el otro; con nos-otros, es decir: yo, tú y el otro (Espinosa, 2017), esta experiencia me ha permitido no olvidar lo humano en las manos y discursos gerencialistas, y desde el encuentro con el otro elevar mi voz en defensa de la vida en el contexto neoliberal y sus discursos.

Al investigar el concepto de la calidad en la educación, comencé a encontrarme con autores que pensaban y problematizaban aquel concepto que parecía incuestionable, pues al parecer la calidad en vez de ser parte de la solución a la crisis educativa actual, era parte del problema. Desde España, Miguel Santos Guerra (1999) me mostraba las trampas subrepticias que implicaba el discurso de la calidad de la educación, y consigo, como con la calidad, la eficacia y la competitividad se convertían en señuelos que condicionan las concepciones, las actitudes y las prácticas de las personas inmersas en la cultura hegemónica. Desde contextos educativos más cercanos, el profesor brasilero Casassus (2007) señalaba que la calidad de la educación se había posicionado sin una discusión previa en el centro de la política educativa, desplazando consigo la educación misma, y que las políticas educativas comenzaron a centrarse en la gestión del sistema y no en la educación. Por otra parte, desde Chile, el profesor Cavieres (2014) me ejemplificaba la calidad de la educación como parte de la privatización de los centros escolares, como parte de la segregación y exclusión que perjudica a los estudiantes de los sectores más empobrecidos de su país.

Entendí que la calidad de la educación era un concepto complejo, que la calidad implicaba entender el contexto neoliberal en que nace, un mundo que está cada vez más colonizado por normas administrativas y jurídicas como diría Bonafé (2014); entender que la colonización de la vida por las normas administrativas alcanzó sin respeto alguno a la escuela.

Comprendí de la mano de mi maestro Rodrigo Jaramillo (2004), Renán Vega Cantor (2012), Alberto Martínez (2004), y Marco Raúl Mejía (2006) entre otros, que este concepto tiene su historicidad de más de 40 años, que su discurso ha sido nutrido por las manos de un sistema económico neoliberal, el cual comienza a llenar a la educación con tintes tecnocráticos; y consigo generar múltiples efectos subrepticios como lo expresaba Santos Guerra en España, pero que para Colombia no eran ajenos.

En efecto la calidad no es un concepto gestado y pensado por la educación, es un concepto originario del discurso empresarial. En un principio, calidad se utilizaba para catalogar características de objetos materiales, pero desde la década de 1980 el concepto se adhiere, de la mano del neoliberalismo, a cualquier servicio público para permitir la comparación, adherencia de la que no se salvó ni la educación, ni el propio ser humano.

El historiador y educador Renán Vega Cantor (2012) señala que el concepto de calidad educativa se usó por primera vez en el año de 1966 con el economista Charles Beevy en su libro "La calidad de la educación en los países en desarrollo”. Posteriormente, en el año de 1968 se retoma 
con el experto de la Unesco Philips Cooms en su libro "La crisis mundial de la educación”. Pero solamente hasta 1983 en los Estados Unidos, con el Informe de la Comisión Nacional de Excelencia en Educación, se habla directamente de «calidad educativa» como un lineamiento de política por parte de un país. Merced a esta comisión se propuso evaluar la calidad de los procesos educativos en la escuela y la universidad, para comparar también la educación en instituciones educativas a nivel internacional.

En este mismo orden y dirección, el educador Alberto Martínez (2004) señala que la política educativa en Latinoamérica encontró su sentido en «el valor central del mercado educativo» (p.11), razón por la cual los principios de calidad, eficiencia y eficacia son considerados por los discursos dominantes como ejes centrales en sus propósitos y contenidos. De ahí que estas políticas educativas, con la participación e influencia del FMI y el BM, resaltan la construcción de una nueva racionalidad educativa basada en los logros de la calidad y la gestión educativa para hacer frente a un mundo más competitivo y globalizado.

Esta crítica no debe reducir su cuestionamiento a la institución educativa, debe extenderse con preocupación a la sociedad y al nuevo orden mundial de la mano de organizaciones internacionales como-OCDE, Banco Mundial, FMI y la Comisión Europea-, lo cual ha hecho que la escuela pierda progresivamente su autonomía para someterse a políticas educativas que respondan a las necesidades de un mundo capitalista.

En la instrumentalización de la educación a manos de la hegemonía económica del sistema capitalista, puedo resaltar que lo corpóreo, el lenguaje con los otros, lo visible e invisible de lo humano parece inscribirse en la uniformidad de una lógica tecnoburocrática; lógica en la cual prima la razón sobre el sentir. Los sistemas educativos buscan como principio rector la certificación, sin detenerse a reflexionar que dicha “certificación” lo único que plantea es una carrera en una pista lineal donde las diferencias humanas deben competir.

Un ejemplo claro de lo anterior lo presenta el actual informe de la OCDE sobre las pruebas Pisa para el 2018 (Revista Semana, 3 de diciembre, 2019) en el cual Colombia obtuvo los resultados más bajos de los países que pertenecen a la OCDE, y según el informe Pisa sus resultados se equiparan a los obtenidos por países no miembros como Albania, Macedonia del Norte y Qatar.

Nuestro país solo superó a España en comprensión lectora, aunque la OCDE aplazó la entrega de los resultados de ese país por encontrar comportamientos inverosímiles en ciertas respuestas. También, llama la atención que al preguntarles a los estudiantes colombianos por su ambiente escolar y aspectos sobre su vida sobresaliera problemáticas como el bullying, problemas familiares y pobreza, entre otros.

Respecto a lo anterior siempre me he preguntado ¿Qué tiene de pedagógico esta clase de pruebas? ¿Cuál es el sentido pedagógico de la competencia? Realmente son preguntas que constantemente me hago como maestro y no encuentro su respuesta; por el contrario, muy de acuerdo con el pensamiento del maestro Maturana (2001) considero la competencia en la educación una problemática que se acrecienta con esta clase de discursos del mundo de la gestión, deteriora las relaciones humanas, y solidifica el sofisma de que para aprender debo ser mejor que los otros (Espinosa, 2017). ¿Será acaso que a nuestro país le va mal en estas clases de pruebas porque son evaluaciones estandarizadas y diseñadas por el interés del mundo del trabajo más no del mundo 
pedagógico? Son pruebas sin contexto, diseñadas y evaluadas por la lógica de agentes económicos; comprendo hoy con mayor fuerza aquellas palabras expresadas hace veintiún años por el silenciado Jaime Garzón (1997) “el problema de la educación es que no tiene nada que ver con las necesidades que tenemos los colombianos”.

El objetivo de nuestro sistema educativo se centra en el competir a nivel mundial, aunque cueste extender jornada educativa como lo hizo Chile, Argentina y México; implementar el modelo de matemáticas de Singapur, para responder a las pruebas estandarizadas; o adaptar el modelo de "Desenvolvimiento da Educação Básica” (IDEB) de Brasil, como se comenzó a implementar con la puesta en práctica del Índice Sintético de Calidad Educativa, proyecto que ha fracasado en países anglosajones como Estados Unidos e Inglaterra. Urge un sistema educativo que piense transformaciones educativas que se desprendan desde las realidades de nuestro contexto social; de lo contrario, continuaremos viviendo una educación de retazos, sin sentido y sin contexto (Toro y Espinosa, 2018).

El pensar hoy la calidad de la educación como maestro, es comprender que su mutación no es más que la actualización de los parámetros de la sociedad del mercado, una tendencia de poder económico con una historicidad muy amplia. Así pues, la calidad de la educación procedente de los contextos de la empresa ha ingresado en la educación sin tener en cuenta los requerimientos, necesidades y la voz de sus principales actores, los maestros y los estudiantes.

Pese a su polisemia, la calidad de la educación se ha impuesto en los lenguajes de la educación como una verdad absoluta y acrítica, pues su solo nombre es sinónimo de éxito y eficacia, al tiempo que denota su comparación con lo que no sería de buena calidad. Mientras la calidad parece la panacea a todos los problemas de nuestro sistema educativo, se invisibiliza el deterioro de lo humano, se ignora la multiplicidad de efectos con los cuales se deteriora los procesos de humanización.

\subsection{Antilatidos de la calidad}

El discurso de la calidad imperante en nuestro sistema educativo es profundamente neoliberal, por lo que ha propiciado la aparición de múltiples efectos que producen lo que yo llamo antilatidos a lo humano, los cuales inciden en las prácticas cotidianas en los miembros de las comunidades educativas promoviendo un sesgo en la exclusión social, al tiempo que se instrumentalizan los procesos educativos, y se reduce la libertad pedagógica. Esta clase de antilatidos transmitidos del mundo de la fábrica a la escuela llegan al extremo de creerse que son lo normal, racional, digno y ético en la educación, de allí que se naturalicen y reconozcan como legitimadores de la educación, a la par que se instaura el olvido de reflexionarles críticamente en lo que hacemos como maestros, sería un acto incoherente.

El primer antilatido es "la competencia como fin en la educación”, la idea de que sólo se aprende a través del competir con los otros, demostrando que se es el mejor; al tiempo que lo humano y la escuela se reduce a un listado posicional, porcentajes y resultados. Se instaura la competencia como el único medio riguroso que sustenta el aprendizaje. Este antilatido deteriora las relaciones humanas, en tanto impone la lupa de ver al otro como un posible rival a superar en una carrera desenfrenada por obtener resultados; no hay tiempo para leer los sentimientos, y la educación se 


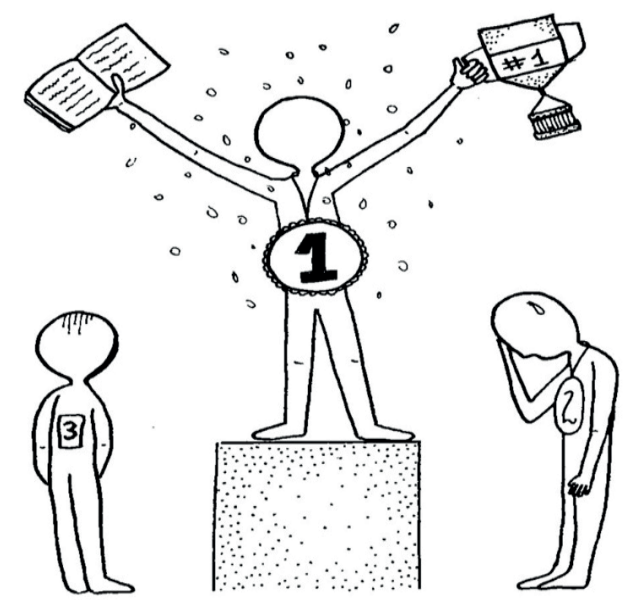

Ilustración 1. La calidad de la educación: ¿Quién es el mejor? María Yesenia Vélez Mazo.

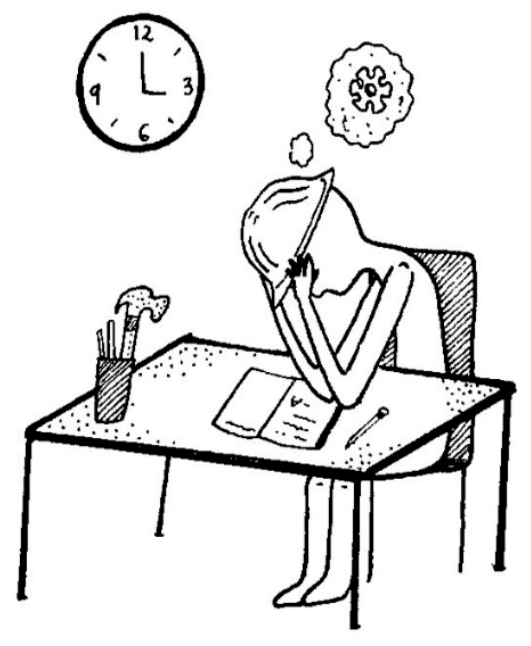

Ilustración 2. El quehacer docente: formatos y más formatos. María Yesenia Vélez Mazo.

positiviza en la razón de los números. Con este discurso neoliberal de la calidad de la educación en nuestras escuelas se está viviendo un panorama reduccionista y comparativo entre los seres humanos; una rivalidad que atenta contra el derecho a ser diferente, lo cual resulta muy preocupante, porque mientras los sistemas educativos continúen pensando que la competencia es el camino, no se comprenderá el verdadero significado de la convivencia (Espinosa, 2017).

El segundo antilatido es "distraer la educación de sus fines formativos", con esto me refiero a que la educación se termina condicionando a los requerimientos del mundo de la gestión, y no al contrario; pareciese tomar forma de embudo, en el cual se antepone la calidad a la educación minimizando la importancia de ésta última (Jaramillo, 2015). Aparece el tiempo de los formatos, estándares, indicadores, planillas y demás diligenciamientos creados por la calidad y desaparecen los espacios para pensar la pedagogía, el contexto, los estudiantes y al propio maestro; ese tiempo es fugaz. El tiempo de la escuela va de forma lineal, una dirección en la cual la diferencia de los contextos colombianos debe estar a la par de los contextos de los países desarrollados.

El tercer antilatido es "la uniformidad de las diferencias humanas”, la educación persigue la naturalización y normalización de los diversos modos de pensar, instaurándose como principio que controla e influye el comportamiento humano. Este proceso agudiza la lucha de todos contra todos, el "sálvese quien pueda" (Boron, citado por Fernández, 2008). Las diferencias humanas se neutralizan con las demandas de la calidad, así sus logros y fracasos dependerán más de su "esfuerzo", “competencia” y "mérito” que de sus factores exógenos a la escuela.

El cuarto antilatido es "la subordinación de la pedagogía y del maestro a los discursos de la calidad”, la pedagogía no sólo se ha atomizado, sino que se le asigna un papel subalterno a los discursos de la calidad de la educación, y más grave aún, la pedagogía se usa como justificación y medio para alcanzar los fines de la estandarización, la mercantilización y el unidimensionalismo que demanda la calidad. La pedagogía, en este caso, se reduce a un aula de clase, se operativiza como si fuese instrumento hecho contenido y se ignora el poder transformativo que posee. Por su parte el maestro, en su práctica pedagógica se le regula a merced de los parámetros de la calidad; presenta una baja remuneración y exceso de trabajo; si no cumple con los condicionamientos del 
discurso de la calidad esta out (fuera) del sistema; mientras vive un currículo diseñado por modelos internacionales es un maestro sin tiempo, cansado, y limitado para y en su pedagogía (Espinosa, 2016). Y al tiempo que al maestro se le distrae en los quehaceres de la calidad, en las escuelas se evidencian cada vez más los giros hacia los procesos administrativos que a los procesos pedagógicos; con los discursos de la gestión se comienza a labrar la despedagogización (Mejía, 2003).

La reflexión no puede quedar en tan sólo una crítica a un avatar tan grande como lo es la calidad de la educación. Es hora que como maestros tomemos posición frente a los discursos del mundo de la gestión, no en el sentido de imponer un nuevo discurso, sino por el contrario, desde nuestra postura crítica y práctica dar el lugar que merece la pedagogía; en palabras de Michel Foucault, es necesario reconocer la "transformación de uno mismo por el propio conocimiento [...]" (Foucault, 2009, p.97). ¡Para qué enseña un maestro sino es para ser transformado por su propio quehacer!

Entre los múltiples antilatidos que se podrían exponer frente a esta realidad, debemos entender que, si se quiere transformar esta situación a través de la práctica pedagógica, debemos partir por hacer visible lo que está invisible en los ojos de la calidad de la educación: ; Reconocer el poder insurgente de lo humano como contra respuesta a esta realidad!

\subsection{Vivir los antilatidos para latir mi corazón: un viaje por la memoria del corazón y razón}

Nací antes de tiempo, lo cual produjo problemas en el desarrollo de mi habla y mi escritura; comencé a hablar a los cinco años, a los siete lograba tartamudear, hoy tartamudeo, aunque no lo parezca. La escuela me hizo creer que era un problema; incluso una maestra le dijo a mi madre que pensara otro espacio para mi formación, ya que retrasaba la clase, no socializaba con los compañeros, y mucho menos participaba de las actividades. No sé si el silencio me hacía un problema. Lloraba al levantarme para ir a la escuela; todos los días me dolía un pie, una mano, la cabeza, el estómago, me dolía mi aprendizaje, creaba siempre una excusa porque la escuela era un lugar de silencio para mí.

La escuela fue un trauma, no creyó en mí, pero descubrí a mi temprana edad que había tres personas que sí creían: mi madre y mis dos hermanos, quienes fueron los que me salvaron. Mi madre me decía: "lo que te propongas puedes hacerlo"; no era la madre de Forrest Gump, pero ahora comprendo el amor de una madre; ese amor puede salvar y mover universos. Todos los días mis hermanos y mi madre se sentaban conmigo a leer a mi ritmo; pasábamos horas haciendo las tareas. Mi hermano mayor me decía: "Hoy vamos a crear historias; yo comienzo hablando y luego tú debes continuar y terminar la historia; luego cambiamos el rol”. Tartamudeaba mucho, pero él no se burlaba, me hacía repetir las palabras hasta que las pronunciara bien, sonreía al escuchar la creación de mis historias y cuentos. De la mano de mí familia y de maestros que le apostaban a la vida comprendí que el aprendizaje se mide por lo que sientes, no por las notas.

Me gradué del colegio Samuel Barrientos Restrepo, y, a diferencia de la escuela, en éste aprendí mucho de los maestros y compañeros; no de los contenidos, sino de lo que hacían. Era un colegio muy pobre; mis compañeros se desmayaban en las formaciones de mera hambre; los maestros, de plata de su bolsillo, pagaban el complemento escolar a los niños más necesitados de mi institución. Encontré maestros y maestras que me alentaban a superarme. Gloria Estela, que siempre tenía un abrazo y una sonrisa para mí, me enseñó que el escribir es una forma de desahogarse, de 
expresión. El viejo Jaime Baena, me enseñó que uno nunca debe callar ante las injusticias. Delante de todo un salón no dejó que el coordinador más gritón, que siempre trataba mal a los estudiantes, humillara y gritara a un compañerito simplemente por estar sentado en una silla de diferente color al del salón. Admiré a este profesor, incluso imitaba su forma de caminar.

Hoy que soy maestro, no soy capaz de decirle a un estudiante que no puede hacer algo como me lo dijo en su momento la escuela. El mayor aprendizaje de la escuela ha sido entender que ésta necesita aprender sobre el escuchar la diferencia, necesita leer lo humano en sus aulas, necesita entender a los niños.

En mi narrativa encuentro dos tipos de escuela: por un lado, la "escuela tradicional", concebida como un lugar que decide por los estudiantes sin entender su contexto, rotula a los estudiantes por lo que saben en lugar de atreverse a escuchar sus historias. Por el otro lado, "la escuela-gente", habitada por maestros con sentido humano, maestros a quienes "no les gusta una educación sin voz", maestros que no creen en la indiferencia de la escuela y del sistema, maestros que creen y apuestan al respeto de las diferencias.

La escuela de mi niñez no me escuchó; hoy que soy maestro escucho a mis estudiantes, y puedo afirmar que: “el escucharles me salvó, me transformó en el mundo de la gestión”, con ellos, he creado una educación basada en el respeto mutuo en desmedro del acelere eficientista y competitivo; el aceptar-nos como portadores de palabras, experiencias y tejidos de humildad me ha devuelto el sentido a la vida y mi oficio de ser maestro.

\section{3 ¿Qué hace latir mi corazón de maestro?}

Soy profesor de ciencias sociales, magister en educación, a veces olvido las fechas o lo que dicen los libros, pero el amor por la enseñanza, la reflexión, la crítica y el respeto por quien habita mi aula de clase nunca lo olvido. En el sistema neoliberal hay dos formas de ser maestro, un "maestro calificador" que pone un número en una planilla, pero sin preguntarse por la vida del estudiante, su contexto familiar y realidad social. Por otro lado, existe el maestro que se pregunta por el contexto familiar y social, por la voz y vida del estudiante, pues para este maestro los estudiantes son más que números en una planilla. "Nadie puede enseñar lo que no ama"; decía, el maestro Estanislao Zuleta (2004), precisamente aprendí a disfrutar y amar la educación escuchando a los estudiantes, comprendí que no hay método educativo más potente que el estar dispuesto a escuchar la palabra del otro; soy un fiel creyente de que la escucha reinventa la educación.

Mi corazón late por ponerse en escena con lo humano que se esconde tras las competencias creadas por un sistema neoliberal, late por lo la diferencia, late por reconocer la palabra y respetar los sueños que habitan en mis estudiantes, late por una educación más sensible y responsable con los otros; diferente, pero sobre todo más humana. Mis latidos del corazón se alejan de una educación palabrera, egocéntrica e individualista producto de una educación que instrumentaliza. El diástole y sístole de mi práctica docente me recuerdan que no puede existir la educación en un ambiente donde el autoritarismo sea el protagonista, ni mucho menos si la desesperanza habita en el corazón de quien enseña, el maestro "no puede enseñar sin esperanza". 
“No hay mañana sin esperanza”, decía Freire (2015), lo creo y como maestro rechazo la idea de que nada podemos hacer frente a la escuela como empresa y mercancía, no me sumo a inclinar la cabeza dócilmente como aquel grillo director de escuela del que nos habló el escritor hondureño Augusto Monterroso (1993), un grillo muy viejo y muy sabio satisfecho de que en la escuela todo siguiera como en sus tiempos. El sistema nos ha hecho grillos sabios, pero el sistema ignora que los grillos vuelan de rama en rama y no se quedan en un solo lugar. Por ello, elevo mi voz con el presente texto para decirle a los maestros y a mis estudiantes que podemos resistir, y aunque, este sistema nos recuerde que somos de carne y hueso, genere rupturas y suela mostrarnos lo frágil que podemos ser, en nuestros corazones de maestros habita un super saber llamado pedagogía, esta nunca es neutra, está en constante transformación, se resiste a la desesperanza, porque la pedagogía es esperanza, y el sistema no puede politizar la mente de un maestro con esperanza, porque sencillamente, este maestro hará lo posible por construir otra educación, pues este es metamorfosis andante.

Como maestro sospecho de aquellos que idealizan sus ideas en la educación, de aquellos que a la par del sistema ofrecen recetas a esta realidad, no existen recetas, la educación sólo puede vivirse, como maestros debemos latir nuestra propia experiencia, y desde ella elevar nuestra voz, por esto, invito a reflexionar y a reinventar mis palabras, metamorfosear esta realidad.

\subsection{Latidos sentipensantes de un maestro y de la pedagogía social}

Es hora de latir la resistencia de nuestras voces como maestros en pro de la humanización en la gestión educativa. Se trata de entender que frente a esta clase de discursos reduccionistas de lo humano hay un maestro, y desde allí urge reconceptualizar y resignificar lo educativo como algo más allá de los contenidos técnicos, la mera instrucción e instrumentalización de aprendizajes. Es necesario latir la singularidad y diferencia, latir al maestro terrenal y finalmente latir otro sentido de la calidad desde la pedagogía social.

"Latir la singularidad y diferencia", significa comprender en la homogeneidad de la calidad de la educación la diferencia en el aprendizaje; reconocer que, aunque la educación sea la misma para todos, no existen dos aprendizajes iguales, pues el aprendizaje siempre es y será singular; es decir, un mundo para cada estudiante. Latir la singularidad y diferencia, implica entender que no es necesario competir para aprender. Por ello, la práctica pedagógica entiende que la diferencia solo puede existir en un espacio educativo en donde no hay disputas por el saber y que no hay que competir por quién es el mejor. Entiende la diferencia como la mayor igualdad entre los seres humanos; le respeta y posibilita por encima del imperio de los indicadores y competencias, su voz; y el posibilitar su palabra y escucha pone en el centro del aula la dignidad a ser diferentes.

En este sentido, desde mi postura ética y profesional de maestro, el resistir no debe entenderse como sinónimo de aguantar los avatares del discurso neoliberal de la calidad de la educación, sino generar formas alternativas a ésta. Así pues, ese silencio-resistencia que se ha ocultado en los maestros, encuentra en los mismos tiempos de la calidad la oportunidad de hacer visible desde su propio contexto su voz con esperanza. Por ello, el "latir al maestro terrenal” en los lenguajes de la calidad de la educación, implica no solamente la capacidad de adaptarse a las demandas de la economía mundial, sino desde su postura educativa promover una transición hacia un nuevo paradigma de pensamiento y de práctica ante la calidad de la educación. 


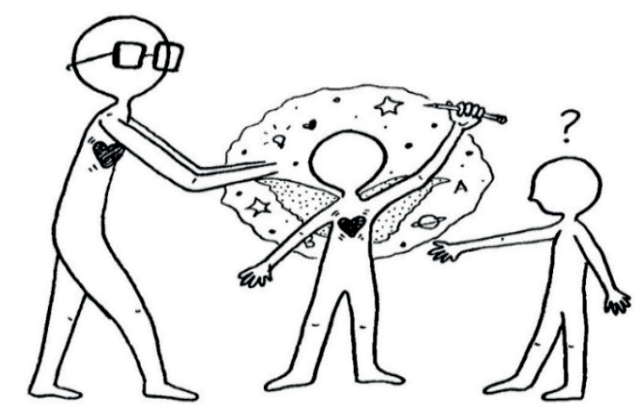

Ilustración 3. Maestro terrenal, maestro de contexto. María Yesenia Vélez Mazo.
El maestro terrenal emerge su práctica no desde los indicadores y logros a alcanzar, sino que parte de la lectura de su contexto, de la escucha y del reconocimiento de la palabra con los otros. Su praxis no se distrae en los tiempos futuros que propone la calidad, tiempos en los que se vive el deber ser para el trabajo y el capitalismo competitivo; por el contrario, comprende la necesidad de reconocer el presente como un "estar siendo", y como posibilidad de iniciar procesos de responsabilidad ética con los otros, de sentipensarnos como miembros de una comunidad educativa en la que también de nuestras acciones depende se afecte a los demás en los discursos indolentes del mundo económico.

Sentir es dolor, indignación, desacomodo desde la práctica pedagógica ante la injusticia que nos ofrece este sistema; sentir no es solo ponerse en el lugar del otro, es condición necesaria para una práctica de aprender a convivir con los otros, no vivir sobre los otros. El maestro terrenal, es comprender que, aunque se viva y no podamos desprendernos del contexto de la calidad, es necesario y urgente vivir la dignidad del maestro, poner los pies en su contexto, y desde allí reconocer su autoridad, saber pedagógico y postura ante la calidad, que en su praxis no olvide que lo humano está por encima de los resultados y lógica económica, y no al contrario.

\section{LATIR OTRO SENTIDO DE LA CALIDAD DESDE LA PEDAGOGÍA SOCIAL}

Propongo con urgencia latir otro sentido de la calidad desde la pedagogía social, es necesario recuperar la discusión pedagógica en los centros educativos, comprender que la pedagogía no puede ser neutra en el mundo de la gestión, ya que es reflexión que muta. Desde la autorreflexión pedagógica se ha permitido elevar la voz ante la despedagogización producto de los discursos de la calidad de la educación en nuestras escuelas; no obstante, es desde el reconocimiento y autoreflexión de la instrumentalización de nuestras prácticas pedagógicas que se ha permitido reconocer la calidad de la educación como parte de la problemática educativa que se vive en la actualidad.

El educador popular y crítico de la calidad de la educación Marco Raúl Mejía (2006) planteaba las "corrientes de la calidad de la educación"4 que se expanden en el contexto latinoamericano y mundial; como maestro, me familiarizo con la cuarta corriente, en la cual se plantea asumir el discurso de la calidad desde una perspectiva crítica, pues considero que el cambio parte del reconocer la existencia del problema, y no negarlo como podría caer la quinta corriente que expone Mejía. Pensar la educación actual sin la influencia del sistema neoliberal sería negar la realidad educativa actual.

4 Para profundizar sobre las corrientes de la calidad de la educación ver a Mejía (2006) “Educación (es) en la(s) globalización (es): Entre el pensamiento único y la nueva crítica", plantea la discusión sobre cómo la calidad es introducida desde distintos ámbitos y permea hoy la discusión latinoamericana de la problemática sin acercarnos a un acuerdo básico sobre ella. La primera corriente habla del traslado de la empresa a la escuela, la segunda define la calidad desde proyectos específicos, la tercera es la que mide la calidad mediante pruebas estandarizadas, la cuarta es asumir la calidad desde una postura crítica y finalmente, la quinta corriente habla de no transigir con la calidad. 


\section{E X P E R I E N C I A S}

No es posible estar en el mundo, con el mundo y con los otros, indiferentes a una cierta comprensión de porqué hacemos lo que hacemos, nos decía Freire (2001). Creo que no es posible estar con el mundo y con los otros frente a los discursos de la calidad de la educación sin comprender nuestro quehacer como maestros; esto remite a una pregunta esencial y transformadora: ¿Cuál es nuestra práctica pedagógica en un contexto educativo a merced del sistema neoliberal?

Partir desde la comprensión del contexto en que nos ha sumergido el sistema neoliberal permite reconocer los derechos pendientes; la desesperanza, para que nazca la esperanza; la indiferencia, para que emerja la resistencia; y entender que son cada vez más las voces que se indignan; voces que se levantan a pensar una educación en la que quepamos todos y no el privilegio de unos cuantos. Por ello, hoy hablamos de que se vive un sistema económico hegemónico, pero también de que hay un telar de pedagogías sentipensantes en situaciones de interlocución y reflexividad para poder hacer y sentirnos con la potencia y la capacidad de construir las resistencias de esta época (Ortega, 2018).

El maestro Alfredo Ghiso (citado en Ortega, 2018), plantea que el pensamiento crítico y la pedagogía en la actualidad colombiana, exige una postura ética y política, porque lo demanda una realidad que no es neutral. Allí encuentro el fuerte de la pedagogía social a la hora de pensar los discursos de la calidad de la educación, pues recordemos que en la exigencia de una postura ética y política la pedagogía es una constante reflexión sobre la práctica pedagógica del maestro, lo cual suscita su propia transformación, un posicionamiento crítico frente al sistema social imperante (Torres, 2009).

Latir otro sentido de la calidad de la educación parte por el asumir como maestro una postura ética y política comprometida con la dignidad humana, con la diferencia y con los derechos del otro. Esa postura ética y política está orientada a la humanización, al respeto por el otro, a entender que el quehacer educativo guiado por opciones ético/políticas no es ajeno a emociones fundantes como la amorosidad (Ghiso, 2018) el cual se expresa en el proceso de enseñanza-aprendizaje.

Pensar la calidad de la educación desde la pedagogía social implica un proceso de formación no para las competencias, sino para el reconocimiento de los contextos; no para el individualismo al que acostumbra la lógica económica del sistema, sino para la convivencia con los otros. La pedagogía social exige desprenderse de absolutismos heredados, coincide con el desafío y la resistencia a la soberanía del Yo, ese que nos vuelve inmunes a la presencia del otro cuando se encierra en su sí Mismo, diría Giroux (2013):

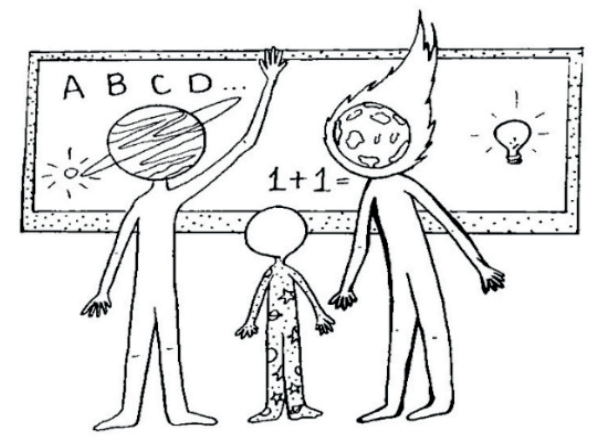

Ilustración 4. Latir otro sentido de la calidad desde las diferencias y derechos del otro. María Yesenia Vélez Mazo.
Lo que se debe desafiar a toda costa es la idea propagada por los gurúes neoliberales que plantea que el desenfrenado individualismo, el interés por uno mismo, y el egoísmo son los valores supremos para modelar la entidad humana, que obtener ganancias es la práctica más importante en una democracia, y que acumular bienes materiales es la esencia de la buena vida (p.20). 
La pedagogía social favorece la humildad, la sociabilidad, el encuentro entre NOS-OTROS, desborda cualquier política educativa utilitarista, cualquier discurso, política o reforma que no tenga en cuenta los sujetos y sus contextos; en esa medida, la presencia y voz de los otros es una condición para pensar la calidad de la educación desde la pedagogía social.

Pensar los discursos neoliberales en la educación, implica comprender que en la escuela de la gestión habitan seres humanos, seres diferentes, seres con dignidades; entender profundamente una política de vida en la cual maestros y estudiantes están comprometidos en construir una con-vivencia en la que se asuma y forme para ser ciudadanos, ciudadanos que respetan los derechos de los demás, piensan y sienten al otro.

Comprender la escuela de la gestión a través de la escucha y palabra me ha permitido encontrarme con la otra cara de una educación de competencias y resultados; me ha permitido romper esa razón indolente, dando lugar a una razón que siente; y sentir es entender la palabra del estudiante que se siente solo, el estudiante que practica cutting y lo esconde bajo su buzo de colegio, el estudiante con problemas familiares, el estudiante con sueños e ilusiones, el estudiante alegre, el estudiante aburrido, el padre de familia con necesidades económicas, el maestro con sueños, el maestro alegre, el maestro aburrido, el maestro confort, el maestro contenido, el maestro transformativo, el coordinador autoritarista, el coordinador que siente, el coordinador alegre y el coordinador estresado, "todos somos gente" ${ }^{5}$, y no un simple dato para alimentar las estadísticas de los indicadores de la calidad de la educación. (Espinosa, 2020)

El papel del maestro en la tarea de pensar otro sentido de la calidad de la educación es fundamental, pues es motor de transformación, es pensamiento crítico que posibilita un vínculo desde y para el reconocimiento de las diferencias. Así pues, podemos hablar de otro sentido de la calidad en la cual el maestro:

- “Tiene voz”. Se indigna frente a cualquier discurso o práctica en detrimento de la educación, de la dignidad humana, de la diferencia. Su voz encarna la postura ética y política comprometida con el mundo de la vida; así mismo, su discurso es contextual, coherente en su pensar y actuar.

- “Es sujeto de praxis”. Comprendiendo que ese sistema tecnocrático establecido en la institucionalidad debe ser retado también desde nuestra praxis. Comprendiendo como diría Torres (2018), que la acción pedagógica busca la transformación subjetiva de los sujetos educativos, afectando, ya sea su conciencia, su cultura, sus creencias, su memoria, sus emociones, su voluntad o su corporeidad. Una transformación subjetiva que nunca perderá el horizonte de la defensa de los derechos en el contexto neoliberal. Para ello, la práctica pedagógica del maestro ha de estar en una constante metamorfosis pedagógica, abrazar un camino de la esperanza que venza el conformismo y el miedo en que nos sumerge el sistema hegemónico, pues como lo diría Freire (1979), superar la desesperanza y conformismos del sistema solo es posible con la inserción crítica de los oprimidos en el mundo para transformarlo. ¡La transformación será posible a través de la propia educación!

5 Hace alusión al poema "Somos gente" de Paulo Freire, en el cual invita a romper cualquier relación de jerarquía en la escuela, la relación dominante/dominado debe desaparecer para la emergencia del proceso educativo. 
- “Reaviva la pedagogía”. La praxis del maestro reacciona ante el pensamiento totalizante que naturaliza el miedo, la desesperanza y el olvido al cambio. A través de la práctica humanista se coloca como centro del proceso educativo la reflexión pedagógica en lugar de las competencias, lo cual permite entrar en una educación problematizadora y no subordinada a las lógicas del mercado. El carácter transformativo de la propia pedagogía permite decolonizar el saber hegemónico, resiste a perpetuar lo establecido, y por el contrario entender que pensar otro sentido de la calidad demanda una pedagogía como un saber hacer, un saber estar y un saber dar en el encuentro (Ortega, 2018).

Latir otro sentido de la calidad de la educación desde la pedagogía social es dar un giro a la pedagogía pensada por la calidad de la educación; implica comprender en la voz del maestro, que el punto de partida de la educación es el contexto y la lectura crítica de éste, un discurso ético-político comprometido con la vida y el respeto a las diferencias humanas. Exige que como maestros comencemos por hacer consciencia y reflexión sobre la educación que tenemos y construimos con los otros, su coherencia con lo que se pretende poner en práctica y con lo que finalmente se lleva a cabo en su compromiso con la vida.

Finalmente, los latidos anteriormente descritos no son una receta ante la calidad, ni mucho menos postulados como panaceas ante las trampas economicistas y reduccionistas que se esconden en los discursos que atentan contra la educación como derecho humano. Los latidos nacen del corazón de un maestro que invita a sentipensarnos más allá de los discursos neoliberales de la calidad de la educación, entendiendo que si bien es difícil pensar la pedagogía y la educación sin hacer referencia a la calidad, pues sería desconocer el contexto mundial, no podemos plegarnos de manera pasiva y acrítica al discurso neoliberal de la calidad, sino que tenemos que hacer visible lo invisible, entender lo humano más allá de los números y la competencia, reconocer el sentir como otra forma de conocimiento, dignificar la práctica del maestro como valor humanizador, recuperar la educación como derecho fundamental y nunca perder la pregunta por lo humano en la educación.

\subsection{Recordé que la pedagogía es hibrida, es problematización constante de mi narración}

La presente reflexión me ha permitido recuperar las tramas en las que como maestro un día me descubrí transformado por aquello que se ha incubado en mi cuerpo para convertirse en narración y reflexión, convertirse en práctica. Este tipo de saber no hubiese sido posible sin la afectación del sujeto (Foucault, 2001); el paradigma neoliberal y el discurso de la calidad de la educación me afectaron como maestro, pero al tiempo, la pedagogía se desató en mí de aquella linealidad en que la dejó la tecnoburocracia de un sistema, y se desató para convertirse en reflexión de mi experiencia y práctica como maestro, porque el sistema, ese que la ató a continuar sus discursos, olvidó que la pedagogía es híbrida, es naturalmente anfibia (Giroux y McLaren, 1998); olvidó que la pedagogía está enraizada a la ética y a un compromiso político con el respeto a la vida y sus diferencias, y que mutaría en defensa de este principio.

La pedagogía se convirtió en una filosofía de vida en el caminar de mi experiencia como estudiante universitario, docente de colegio privado y maestro de universidad; suscitó una problematización de mí ser maestro en el contexto neoliberal permitiendo resignificar mi praxis a través de 
la narración autobiográfica. De la mano de la memoria, la escritura y la esperanza comencé a narrarme, no con el sentido de anecdotizar mi praxis sino como posibilidad de sentir-me, pensar-me y transformar-me ante los discursos oficiales, estandarizados y hegemónicos de un sistema.

No puedo verme a mí mismo como un receptor pasivo de aquellos discursos que descuartizan la educación como derecho humano. La Práctica Pedagógica Sentipensante que nació en mis tejidos experienciales con los otros, esos al que el sistema pensaba que iba a verlos como resultados o números, la pedagogía me enseñó a verlos como seres humanos, seres con dignidades, seres con derechos. Fueron esos otros quienes me enseñaron a enseñar y a creer en mi práctica pedagógica, una práctica que se hace en conversación, entre palabras y acciones, pensamientos y emociones, resistencias y esperanzas, contexto y praxis. Una praxis que no puede pensarse sin el contexto, sin la escucha y el diálogo, sin la escritura e investigación, una praxis que exige mutar.

¡Hoy, tiempo y espacio de los discursos neoliberales en la educación, reafirmo mi esperanza de reavivar la pedagogía en el centro de la educación! Este proceso investigativo ha significado la posibilidad de invitar-me a no perder la capacidad de autonomía, voluntad, esperanza, humildad y sueño de creer que podemos construir otra educación posible.

La narración biográfica nace, precisamente, cuando acontece algo imprevisto, cuando se altera algo que se ha asumido como "normal", dice Ortiz (2014). Asumí en un comienzo de mi experiencia la calidad de la educación como "normal”, e incluso llegué a verle como incuestionable, pero siguiendo a Ortiz (2014), hacer investigación narrativa es atravesar una puerta que ha sido condenada por la lógica; y en mi caso concreto, el atravesar la puerta narrativa de mi experiencia permitió comprender las transformaciones suscitadas por la emergencia de una Práctica Pedagógica Sentipensante ante la lógica que burocratiza e instrumentaliza la educación. Decidí inscribirme en un "estar siendo" que exige repensar el presente, leer el contexto; mi práctica se enraizó en el reconocimiento de la escucha y palabra del otro, posibilitando formas de pensar y de vivir, desnaturalizando aquellos lenguajes y discursos que silencian la voz de las diferencias, pues entendí mi práctica como una lucha, una resistencia que, como diría Rigal (2004) la praxis social está destinada a ser productora de sentido, con intencionalidad de transformación social.

\section{PRÁCTICA PEDAGÓGICA SENTIPENSANTE: UNA FORMA DE CONSTRUIR MI CAMINO DE VIDA}

El concepto sentipensante nace de aquellas sabias palabras de los pescadores en San Benito Abad (Sucre) al sociólogo Orlando Fals Borda (citado en Lizaraso, 2017): "Nosotros actuamos con el corazón, pero también empleamos la cabeza, y cuando combinamos las dos cosas así, somos sentipensantes", un concepto que ha inspirado a poetas, tal fue el caso de Eduardo Galeano (2000), quien le definió como "aquel lenguaje que dice la verdad”.

En el campo educativo, significa "aprender a sentir y pensar con el otro, no sobre el otro" (Espinosa, 2014), ser “sujetos de praxis” (Ghiso, 2004), o como diría Castro (2018), un sentipensante es un enamorado de la vida, un revolucionario que reúne lo emocional con lo cognitivo haciendo ruptura con el racionalismo hegemónico.

“Práctica Pedagógica Sentipensante”, es una práctica en constante mutación, en la cual el 
"sentir, pensar y actuar" se transforman en resistencia a los discursos educativos reduccionistas de las diferencias humanas; implica reconocer que la educación no consiste en una carrera por el competir con los otros, sino en aprender a sentir-nos y pensar-nos con los otros (Espinosa, 2014). Su centro no son las competencias, sino la comprensión y reconocimiento de la diferencia como la mayor igualdad entre los seres humanos; el respeto a la dignidad del otro es su cosmovisión; la pedagogía no es para el tiempo del mercado, sino para el tiempo de lo humano. Es una pregunta constante por la experiencia y el quehacer del maestro en tiempos de adherencia y deformación ante los conceptos coetáneos de la empresa y el mundo neoliberal (Espinosa, 2018).

A lo largo de mi experiencia con los otros, he comprendido la importancia de reconocer otras formas de construir caminos con la vida, con lo humano, con la diferencia y la naturaleza, pues como diría Skliar (2005) "las diferencias nos constituyen como humanos", no debemos domesticarlas, ni hacerles talla única en pensar y ser, no hay nada más atentatorio a la dignidad humana que uniformar su diferencia.

Esta práctica pedagógica ha posibilitado un tejido dialógico con otros rostros, por ello, considero el "aula como lugar de palabra y escucha", para adentrarme en otros mundos posibles, mundos en los que se indaga por la realidad de mis estudiantes para comprenderla mejor; significa alejarme por un momento del libro para escuchar la palabra del estudiante (Espinosa, 2015).

[...]Al sentir y pensar la escuela he comprendido como maestro en el mundo de la gestión que la escuela es un espacio emocional, vivo, donde circula un universo de diferencias pensantes. El sentipensar como maestro la educación actual corresponde a una respuesta política insurgente frente aquellos discursos que niegan las diferencias, esos mismos que roban el tiempo para leer lo humano más allá de los resultados, discursos que imponen la razón y se olvidan que somos seres de emociones. (Espinosa, 2020).

Al ser maestro de una institución educativa privada volví a encontrar aquella escuela tradicional que marcó mi niñez, una escuela que parece no haber cambiado, una escuela que sigue marginando, excluyendo y negando al otro. Pero en esta ocasión hay una gran diferencia: el niño fragmentado por esa escuela tradicional se convirtió en maestro, un maestro dispuesto a romper con esa gramática neoliberal contraria al respeto. Como maestro, decidí apostar a resistir, no en cuestión de combate, sino como oportunidad de re-creación desde la propia crisis; por ello, mi experiencia en la institución privada va a encontrar tensiones y posibilidades de cambio con los otros, pero esencialmente ese cambio va a tejer mi identidad profesional docente como un modo de “estar" y de "ser” en el mundo.

Entendí que el maestro que reflexiona su experiencia y la compone narrativamente puede contar su verdad a otros, suscita una oportunidad para el diálogo, el pensar, el sentir, la indignación, la voz, o como lo dijera Bruner (2003), construir comunidad de interpretación. El siguiente cuadro ilustra la tensión educativa que ha caracterizado mi experiencia con el discurso de la calidad de la educación y mi práctica pedagógica sentipensante. (Ver Tabla 1). 


\section{E X P E R I E N C I A S}

Tabla 1: Tensiones en mi experiencia como maestro entre la calidad de la educación y mi práctica pedagógica sentipensante

\begin{tabular}{|c|c|c|}
\hline Conceptos & $\begin{array}{c}\text { Experiencia con los discursos de la calidad } \\
\text { de la educación }\end{array}$ & Práctica pedagógica sentipensante \\
\hline $\begin{array}{l}\text { La institución } \\
\text { Educativa }\end{array}$ & $\begin{array}{l}\text { La institución educativa se asemeja a la } \\
\text { empresa, está a merced de los estándares } \\
\text { e indicadores de la gestión. Homogeniza } \\
\text { las diferencias humanas. }\end{array}$ & $\begin{array}{l}\text { La institución educativa no es una empresa, ni la } \\
\text { educación un negocio. Se configura en un proceso de } \\
\text { reconocimiento y respeto a las diferencias humanas. }\end{array}$ \\
\hline $\begin{array}{l}\text { Concepto de } \\
\text { educación }\end{array}$ & $\begin{array}{l}\text { Se entiende la educación como un asunto } \\
\text { de productividad, de competencias y de } \\
\text { supervivencia en el saber. ¡Vales por lo } \\
\text { que sabes y no por lo que sientes! }\end{array}$ & $\begin{array}{l}\text { Se entiende como un proceso de aprendizaje en el } \\
\text { sentir y pensar con los otros, no sobre los otros. Se } \\
\text { aprende a respetar las emociones, el pensamiento y las } \\
\text { diferencias. Se cimenta en la palabra y la escucha. }\end{array}$ \\
\hline El estudiante & $\begin{array}{l}\text { Se ve como un resultado, un número } \\
\text { en la lógica del aprender a competir. Se } \\
\text { homogeniza su aprendizaje, deben pensar } \\
\text { igual y responder de la misma forma en las } \\
\text { pruebas estandarizadas. La evaluación dirá } \\
\text { qué clase de estudiante es: bueno o malo. } \\
\text { Se invisibiliza su voz. }\end{array}$ & $\begin{array}{l}\text { La práctica pedagógica parte de escuchar la voz de los } \\
\text { estudiantes. Son seres sentisapientes (que saben y si- } \\
\text { enten), no son un número, todos tienen aprendizajes } \\
\text { que compartir. A partir de su escucha se realiza trans- } \\
\text { formaciones en la propia práctica del maestro. }\end{array}$ \\
\hline Aula de clase & $\begin{array}{l}\text { El aula es uniforme y homogénea. Debe } \\
\text { caracterizarse por el orden y el riguroso } \\
\text { silencio. Los estudiantes son receptores } \\
\text { del saber. }\end{array}$ & $\begin{array}{l}\text { Es un aula de la palabra y la escucha en la cual todos } \\
\text { tienen voz. Se rompe con la linealidad clásica y operante } \\
\text { de la escuela. Los estudiantes proponen estrategias } \\
\text { para el saber, unos aprenden de otros. }\end{array}$ \\
\hline La evaluación & $\begin{array}{l}\text { La evaluación es estandariza, y se configura } \\
\text { en la herramienta más eficaz de promover } \\
\text { la calidad de la educación. La evaluación } \\
\text { asigna un valor a la dignidad de la persona } \\
\text { y los centros educativos. Encamina a una } \\
\text { competencia de nunca acabar, y deteriora } \\
\text { las relaciones humanas por descubrir los } \\
\text { mejoresy los perdedores. Genera temor en } \\
\text { los estudiantes. }\end{array}$ & $\begin{array}{l}\text { Se comprende como un camino de aprendizaje, y no de } \\
\text { temor y apatía. La nota no es la finalidad, es lo forma- } \\
\text { tivo. La evaluación es un complemento al proceso de } \\
\text { enseñanza-aprendizaje, se transforma la linealidad del } \\
\text { a,b,c,d al que acostumbró el sistema, se interactúa con } \\
\text { la propia prueba, la cual tiene en cuenta la voz del mae- } \\
\text { stro y del estudiante. La evaluación es una construcción } \\
\text { conjunta. }\end{array}$ \\
\hline El maestro & $\begin{array}{l}\text { Un maestro limitado en su práctica } \\
\text { pedagógica. Es vigilado y se le suele ver } \\
\text { como un obrero. Su discurso debe marchar } \\
\text { en pro de la excelencia y la calidad; al } \\
\text { tiempo, el sistema suele crear una zona } \\
\text { de confort pese a sus inconformidades } \\
\text { laborales. Debe sumarse y promover la } \\
\text { cultura de la competencia. }\end{array}$ & $\begin{array}{l}\text { Es un maestro inconformista, un maestro que está en } \\
\text { una formación constante, metamorfosea su práctica a } \\
\text { partir de la interacción con los otros. Desburocratiza los } \\
\text { discursos reduccionistas de lo humano, y le apuesta a } \\
\text { una educación para la vida. Aunque no puede desatarse } \\
\text { de las lógicas de la calidad, se transforma al interior de } \\
\text { esta propia lógica, su discurso y práctica está compro- } \\
\text { metida con el contexto, las diferencias y la vida. Lucha } \\
\text { por la dignificación de su labor docente. }\end{array}$ \\
\hline
\end{tabular}

Fuente: Espinosa (2020). Práctica Pedagógica Sentipensante como resistencia ante los discursos de la calidad de la educación: La Experiencia Biográfica Narrativa de un Maestro de una insititución educativa privada. 


\section{E X P E R I E N C I A S}

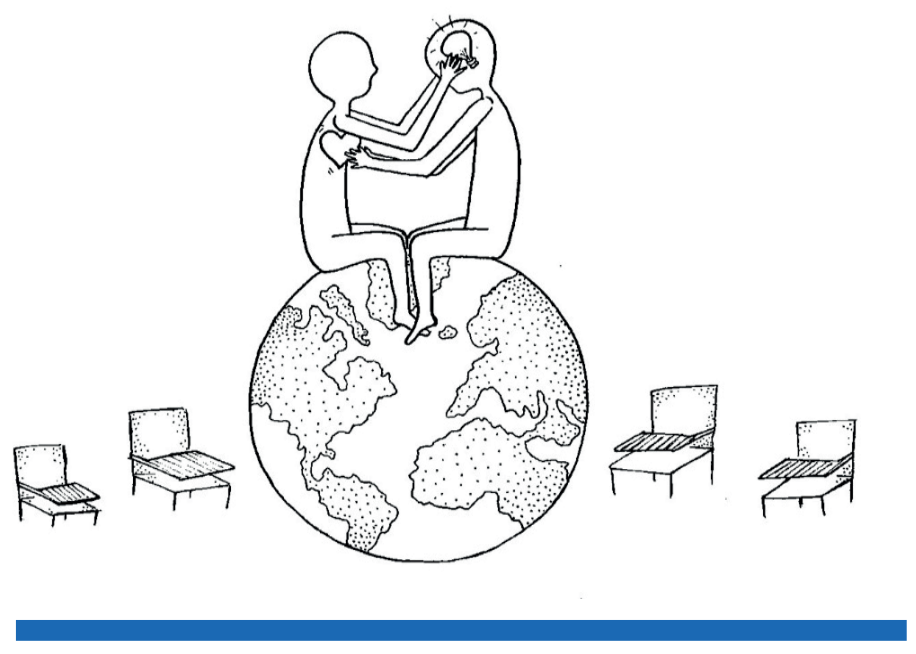

lustración 5. Sentipensar la educación. María Yesenia Vélez Mazo.
Decidí pensar-me desde el problema, pensar-me desde el centro de la gestión y de los discursos de la calidad y cómo estos, fracturan, agrietan y tocan al maestro; consideré necesario vivir aquello que se nos impone (narrativa oficial profesional), para que de esta forma, "emergiera mi voz en el mundo", la voz con los otros, y de cara esto, transformarme en mi identidad y práctica pedagógica, pues, lo que se impone y quiere regularnos, ignora que nuestra identidad está en continua transformación, nunca es y será estática.

La práctica pedagógica sentipensante no es una receta pedagógica; no busca imponer o cambiar a los otros, pues sería caer en lo que tanto crítico, un discurso impuesto; por el contrario, se trata de una reflexión y desacomodo de mi praxis como maestro, una emergencia en mi construcción de identidad profesional docente, una posibilidad de construir mi palabra y re-pensarla; y al tiempo, invitarte a pensar la tuya en el contexto de la gestión educativa.

\section{UN LLAMADO A CONTINUAR SENTIPENSANDO...}

Pensar la calidad de la educación es comprender que el capitalismo ha impuesto con la globalización del mercado giros insospechosos disfrazados en discursos que pregonan una educación más igualitaria y como derecho humano. La estandarización y el neoliberalismo se fusionan de manera desbordante en detrimento de la educación, mientras al maestro se le reemplaza su tiempo pedagógico para dar lugar al tiempo de los indicadores, llenar formatos, fichas, diseñar pruebas estandarizadas; al tiempo que no se les respeta, y trata como simples cuidadores de niños.

Es necesario desconfiar de aquellos discursos educativos que no aceptan la singularidad de las diferencias, sino que se esfuerzan por desdibujar y uniformar los diversos ritmos de aprendizajes. A veces, estos discursos no están diseñados para que se conviva con los otros, sino para que se compita con ellos.

A continuación, a modo de consideraciones finales expreso otras reflexiones a tener en cuenta en futuras discusiones e investigaciones a propósito de esta realidad que se acrecienta en el actuar del maestro:

- Es necesario la recuperación del valor humanizador de la escuela, propendiendo por la recuperación de la educación como derecho humano, evitando que continúe su mutación en mercancía. En este caso, llama la atención cómo los discursos nacientes de la empresa, por ejemplo "la calidad de la educación”, se usan como excusas para privilegiar elementos mercantiles por encima de los ideales de formación, al tiempo que se estigmatizan las diferencias humanas y se introduce un sesgo social entre lo público y lo privado. 
- Es fundamental una postura crítica por parte del maestro ante el discurso neoliberal de la calidad de la educación. Es de aclarar que no está en cuestión la educación excelente, ni mucho menos el valor de la educación para el buen vivir, lo que es realmente preocupante y debe llamar la atención de todos estos discursos es la multiplicidad de efectos e implicaciones en detrimento de lo humano.

- Es hora de comprender que la educación es mucho más que una prueba estandarizada, ya que esta clase de pruebas coartan la diferencia, no pueden medir la creatividad, las destrezas de escritura, la resolución de problemas sociales o habilidades de pensamiento crítico. La escuela no es una empresa ni la educación un negocio.

- La singularidad, voz y pedagogía que caminan con el maestro no se pueden instrumentalizar en las manos economicistas y reduccionistas de lo humano, porque su singularidad, voz y pedagogía son transformación y responsabilidad de vida para con los otros. La calidad y cualquier discurso que pretenda convertir la educación en un bien de consumo, encontrará su tensión en el maestro, porque el maestro es reflexión andante que metamorfosea su propia práctica, y ese metamorfosear reemplaza cualquier vestigio en detrimento de la dignidad humana.

- Uno de los riesgos frente al tema de la calidad de la educación se asocia con la indiferencia en el uso conceptual riguroso (Jaramillo, 2004). La ausencia de debate sobre el concepto, sus discursos y consecuencias en la educación ha sido una realidad, o más bien lellamaría uno de sus efectos en los sistemas educativos, pues su solo nombre se asimila a garantía de éxito, por ende, no debe cuestionarse, y cualquier discurso educativo que no lleve explicito el apellido de calidad carecerá de valor. La calidad es un concepto polisémico y no es neutro, lleva la delantera con las competencias, estándares, indicadores y demás parámetros creados para la educación; no obstante, el panorama no puede caer en la desesperanza, pues el pensar la desesperanza ha de partir por creer en la esperanza. La esperanza parte del presente, mientras a la calidad le alzan en los hombros de la gestión, hay maestros que creen que esta realidad educativa no es la única construcción posible, creen en otra forma de calidad no para el tiempo del mercado, sino para el tiempo de los derechos; maestros que comprenden y viven la dignidad humana, no como punto de partida sino como punto de llegada (Espinosa, 2014).

- Hoy más que nunca creo que la esperanza debe ser motivo de reflexión en las aulas de la gestión educativa, "el cambio es difícil, pero es posible", nos dijo Freire (2004), creo en ello, y estoy convencido de que este no vendrá del propio sistema al que criticamos, ni del pesimismo, o mucho menos del pedir recetas pedagógicas que no existen; el cambio parte de nosotros mismos como maestros. Con respecto a la esperanza al cambio, el pedagogo crítico Peter Mclaren (2005) quiere ser partícipe de esta reflexión, levanta su mano para recordarnos el poder que subyace en la pedagogía, pues esta significa “curar, reparar y transformar el mundo"; por ello, para él, un educador que se asuma a pensar diferente será sensible a las palabras, los sentires, los haceres, los gestos y los contextos en los cuales enseña y desde los cuales aprende en la relación con los demás, una transformación que dependerá necesariamente de las relaciones y conocimientos 
que mutuamente puedan compartir y tejer en la praxis educativa. Así mismo, pienso que no podemos hablar de un proceso trasformador con los otros, si primero el maestro en su aula de clase "no se cura, se repara, se deconstruye y reconstruye" para poder transformar el mundo. No olvidemos que el sistema neoliberal no se detiene; pero así mismo, la esperanza en el corazón de los maestros no se acaba, se transforma, y al transformarse cambia todo a su alrededor.

Estas reflexiones, de fuertes latidos del corazón de un maestro, le invita a entrar al debate, a repensar-nos y sentir-nos en el contexto de la calidad, a construir desde ella propuestas y modificar nuestras prácticas pedagógicas sin perder el horizonte pedagógico del respeto a las diferencias humanas, la dignidad del maestro y su práctica. Me esfuerzo cada día en no ceder a la naturalización del sistema, por ello mismo, busco mantenerla, para que sea visible la pregunta por lo humano en mí actuar. Es claro la intensión de la presente reflexión al resignificar la praxis del maestro en los tiempos de la gestión; no obstante, no puedo eludir que precisamente ella es también hija de la calidad de la educación, pero también asumo que es ella misma, la que ha suscitado que como maestro transforme mi praxis. Creo que la indiferencia pesimista de que el cambio no es posible nunca podrá impedir que la transformación se geste en maestros que creen en otra educación. Por ello, sin temor alguno, y con una profunda esperanza, comparto mi experiencia, mi voz y mi práctica con el ánimo de encontrar otras voces que se sumen al cambio, pues como diría Okri (1997) "si cambiamos las historias a través de las que vivimos es muy probable que cambiemos nuestras vidas”; por ello, decidí como maestro transformar mi relato, pues los relatos transforman (Rivas, 2007).

\section{REFERENCIAS}

Bonafé, J. M. (2014). Pedagogía de la desobediencia. Foro de Educación, 12(17), 17-19.

Bruner, J. (2003). La fábrica de historias. Derecho, literatura y vida. España, Fondo de Cultura Económica.

Casassus, J. (2007). El precio de la evaluación estandarizada: la pérdida de calidad y la segmentación social. Revista Brasileira de Política e Administração da Educação / Periódico científico editado pela anpae, 23(1).

Castro, P. (2018). Sentipensando la praxis educativa universitaria: Un lugar para la sensibilidad a partir de la relación esteta maestro/educando. (Tesis de Maestría). Universidad de San Buenaventura, Colombia. Recuperado de https://n9.cl/eOlt

Cavieres, E. (2014). La calidad de la educación como parte del problema Educación escolar y desigualdad en Chile. Revista Brasileira de Educação. Vol. 19 n. 59. Río De Janeiro (Brasil): ANPEd - Associación Nacional de Posgraduación y Pesquisa en Educación.

Espinosa, D. (2014). Una escuela "sentipensante" para el reconocimiento y práctica de los derechos humanos. Rastros Rostros, 16(30). https://doi.org/10.16925/ra.v16i30.824

Espinosa, D. (2015). Hacia una pedagogía de la escucha, en la escuela el otro tiene mucho que decirnos. Educación y Cultura. Fecode. No. 107.

Espinosa, D. (2017). La escuela no es una empresa, ni la educación un negocio. Praxis Pedagógica, 17(21), 65-78. https://doi.org/10.26620/uniminuto.praxis.17.21.2017.65-78 


\section{E X P E R I E N C I A S}

Espinosa, D. (2016). Algunos síndromes de la escuela en Colombia: hacia una pedagogía del encuentro. Educación y Cultura. Fecode. Edición 117.

Espinosa, D. (2018). Prácticas pedagógicas sentipensantes: un encuentro con el otro. Educacióny Cultura. No. 126. Fecode.

Espinosa, D. (2020). Práctica Pedagógica Sentipensante como resistencia ante los discursos de la calidad de la educación: La Experiencia Biográfica Narrativa de un Maestro de una institución educativa privada (tesis de maestría). Universidad de Antioquia. Medellín,Colombia.

Fernández, M. (2008). Hacia una pedagogía de las diferencias desde los aportes de la propuesta de Paulo Freire. Paulo Freire. Contribuciones para la pedagogía.

Foucault, M. (2001). La hermenéutica del sujeto. Buenos Aires, Fondo de cultura económica.

Foucault, M. (2009). Cómo nace un libro experiencia. En El yo minimalista y otras conversaciones. Buenos Aires, La Marca Editora

Freire, P. (1979). Pedagogía del Oprimido. México: Siglo XXI editores.

Freire, P. 2001 Pedagogía de la indignación (Madrid: Morata).

Freire, P. (2004). El grito manso. Siglo XXI.

Freire, P. (2015). Pedagogía de los sueños posibles. Por qué docentes y alumnos necesitan reinventarse en cada momento de la historia. Buenos Aires: Siglo XXI. 187 páginas. ISBN: 978-987-629-604-5

Galeano, E. (2000). El libro de los abrazos. México: Siglo XXI editores.

Garzón, J. (1997). Conferencia en la Universidad Autónoma de Occidente, Santiago de Cali.

Ghiso, A. (2004). Entre el hacer lo que se sabe y el saber lo que se hace: una revisión sui géneris de las bases epistemológicas y de las estrategias metodológicas. En: Sistematización de Experiencias -Propuestas y debates. 7-22. Dimensión Educativa.

Ghiso, A. (2018). Entre el legado de los que me preceden y mi quehacer educativo. En: Educación Popular y Pedagogías Críticas en América Latina y el Caribe. Corrientes emancipatorias para la educación pública del siglo XXI. CLACSO.

Giroux, H. 2013 “La Pedagogía crítica en tiempos oscuros” en PraxisEducativa, N²5, pp.13-26. Recuperado de http://www.redalyc.org/articulo.oa?id=153129924002

Giroux, H. y McLaren, P. (1998). Sociedad, cultura y educación (Madrid: Miño y Dávila).

Jaramillo, R. (2004). La calidad de la educación. Hacia un concepto de referencia. Revista Educación y Pedagogía, [S.1.], n. 38, p. 91-100, oct. 2010. ISSN 0121-7593. Recuperado de: https://n9.cl/uu0j

Lizaraso, D. (Productor). (2017). Orlando Fals Borda: la verdad sentipensante. [Youtube]. Canal22.

McLaren, P. (2005). La vida en las escuelas: una introducción a la pedagogía crítica en los fundamentos de la educación. Siglo XXI.

Martínez, A. (2004). De la escuela expansiva a la escuela competitiva: dos modos de modernización educativa en América Latina (Vol. 5). Anthropos Editorial.

Maturana, H. (2001). Emociones y lenguaje en educación y política. Santiago de Chile. Chile. Hachette. 


\section{E X P E R I E N C I A S}

Mejía, M. (2003). Educaciones y pedagogías críticas desde el sur. Cartografías de la educación popular. Viceministerio de Educación Alternativa y Especial. La Paz, Bolivia.

Mejía, M. (2006) Educación(es) en la(s) globalización(es) I: Entre el pensamiento único y la nueva crítica. Bogotá, Colombia. Ediciones desde abajo.

Monterroso, A. (1993). Cuentos y fábulas. Circulo de Lectores.

Okri, B. (1997). A Way of Being Free. Londres: Phoenix House.

Ortega, P. (2018). La educación popular y su resignificación en la pedagogía crítica. En: Educación Popular y Pedagogías Críticas en América Latina y el Caribe. Corrientes emancipatorias para la educación pública del siglo XXI. CLACSO.

Ortiz, N. (2014). Pensamiento narrativo y saber pedagógicos apuntes para acompañar la escritura de trabajos de grado y tesis narrativas. Taller de la Palabra. Universidad de Antioquia.

REVISTA SEMANA. (2019). Colombia, el país de la Ocde con los resultados más bajos en las pruebas Pisa 2018. Recuperado de https://n9.cl/3wb6

Rigal, L. $2004 \mathrm{El}$ sentido de educar. Crítica a los procesos de transformación educativa en Argentina, dentro del marco Latinoamericano (Buenos Aires: Miño y Dávila).

Rivas, J. I. (2007). Vida, experiencia y educación. La biografía como estrategia de conocimiento. En Sverdlick, I. (comp.). La investigación educativa. Una herramienta de conocimiento y de acción. Buenos Aires: Novedades Educativas.

Santos, M. (1999). Las trampas de la calidad. Acción pedagógica, 8(2), 78-81. Recuperado de https:// dialnet.unirioja.es/descarga/articulo/2973330.pdf.

Skliar, C. "Poner en tela de juicio la normalidad, no la anormalidad. Políticas y falta de políticas en relación con las diferencias en educación”, Revista Educación y Pedagogía. Universidad de Antioquia, Facultad de Educación, Vol. XVII, N. 41 , pp. 11-22. Medellín- Colombia.

Toro, E. \& Espinosa, D. (2018). Un sistema educativo de retazos y sin sentido: Es hora de una educación para el contexto. Educación y Cultura. Fecode. Edición No. 124.

Torres, A. (2009). Educación Popular y paradigmas emancipadores. Pedagogía y Saberes. N. o 30. Universidad Pedagógica Nacional. Facultad de Educación, pp. 19- 32.

Torres, A. (2018). ¿Dónde está lo crítico de la educación popular? En: Educación Popular y Pedagogías Críticas en América Latina y el Caribe. Corrientes emancipatorias para la educación pública del siglo XXI. CLACSO.

Vega, R. (2012). La calidad educativa una noción neoliberal propia del darwinismo pedagógico. Rebelión. Recuperado de https://n9.cl/6yfw

Zuleta, Estanislao. (2004). Educación y democracia: un campo de combate. Hombre Nuevo Editores, Fundación Estanislao Zuleta, Medellín-Colombia. 